\title{
A relação dos usuários especialistas e não-especialistas com as fontes de texto: distinção e atribuição de conceitos subjetivos
}

\author{
The relationship of experts and non-experts users with text typefaces: distinction \\ and assignment of subjective concepts
}

Luiza Falcão, Solange Coutinho

\author{
tipografia, semântica, usuários
}

A proposta básica dessa pesquisa é a exploração das possibilidades semânticas das fontes de texto e o entendimento de como esse potencial significativo é encarado pelos dois principais grupos de usuários das fontes: os especialistas e os não-especialistas. Para tanto, foram aplicados questionários com 40 usuários especialistas e 40 usuários não-especialistas, entre designers gráficos e pessoas de diferentes profissões, utilizando para teste 12 fontes de texto. A aplicação dos questionários visa investigar, em seu primeiro momento, se os usuários conseguem perceber diferenças entre as fontes próprias para a composição de textos longos, e posteriormente, se conseguem atribuir características subjetivas às mesmas. $O$ artigo apresenta o processo de construção desse estudo e suas principais conclusões.

typeface, semantics, users

The basic purpose of this research is to explore the semantic possibilities of text typefaces and understanding how this significant potential is seen by the two main groups of users of fonts: experts and non-experts. To this end, questionnaires were conducted with 40 expert users and 40 non-expert users, graphic designers and people from different professions, using for the test 12 text fonts. Questionnaires investigate, at first, if users can perceive differences between the text fonts, and later, if they can assign subjective characteristics to them. The article presents the construction process of this study and its main conclusions.

\section{Introdução}

Este estudo foi motivado pelo alto grau de complexidade do entendimento da relação entre os usuários e as fontes de texto, especialmente no que diz respeito a sua dimensão semântica. As tipografias próprias para a composição de textos longos tendem a ser mais discretas em suas formas, de modo a possibilitarem o reconhecimento dos seus caracteres pelos leitores com o mínimo de dificuldade e o máximo de agilidade. O espaço para inovações formais onde o designer de tipos pode explorar desenhos mais diferenciados é escasso, porém existente.

A proposta básica dessa pesquisa é explorar as possibilidades semânticas das fontes de texto e entender como esse potencial significativo é encarado pelos dois principais grupos de usuários das fontes: os especialistas e os não-especialistas. Para este estudo, o grupo dos especialistas é composto por designers gráficos com formação superior e com mais de dois anos de atuação profissional na área e o grupo dos não-especialistas é composto por pessoas de diferentes formações acadêmicas (que já possuíssem ou em fase de conclusão de curso superior). Em ambos os grupos os participantes possuem idade entre 20 e 60 anos. $O$ processo de construção desse estudo e suas principais conclusões serão apresentados a seguir. 


\section{Tipografia e significado}

O primeiro passo da construção desta pesquisa foi um levantamento bibliográfico sobre estudos que abordam, sob diferentes óticas, a relação entre tipografia e significado. Dentre eles, destacam-se as pesquisas de Brumberger (2003), Mackiewicz \& Moeller (2004), Li \& Suen (2010) e Dyson \& Stott (2012). Tais autores admitem que o assunto ainda precisa de uma investigação mais profunda devido ao alto grau de dificuldade presente em investigações desta natureza. Outros estudos abordam a relação entre tipografia e significado utilizando uma outra abordagem: o entendimento de quais os atributos formais dos caracteres que são capazes de carregar uma maior carga de significado. Dentre as teorias que conjecturam sobre como é possível atribuir diferentes conceitos subjetivos às fontes ao manipular seus aspectos intrínsecos, destacam-se as publicações de Van Leeuwen (2006), Samara (2007) e Falcão \& Aragão (2012). Tais pesquisas propõem alguns grupos de características subjetivas passíveis de serem atribuídos aos tipos após a observação de alguns aspectos formais pré-definidos. É importante frisar que tais estudos apresentam algumas das potencialidades significativas da tipografia, pois consideram unicamente o desenho dos caracteres como fatores determinantes sua atribuição, ignorando os demais fatores presentes na utilização dos tipos como, por exemplo, o conteúdo do texto, os aspectos culturais dos usuários, entre outros.

Após a compilação das pesquisas que tangenciam a relação entre tipografia e significado, foi procurado entender como os designers de tipos, sujeitos envolvidos no processo projetual de fontes de texto, assimilam sua capacidade semântica e equacionam seus aspectos técnicos e conceituais ao longo do projeto de fontes dessa natureza. Para tanto, foram realizadas entrevistas semiestruturadas com designers de tipos brasileiros e as informações recolhidas ao longo do processo também foram utilizadas como embasamento para a formatação dos questionários.

\section{A formatação da pesquisa}

As informações reunidas no levantamento bibliográfico e os dados fornecidos pelos designers de tipos foram utilizados como base para a elaboração dos questionários, a principal ferramenta de coleta de dados desse estudo. O intuito da aplicação desses questionários é investigar se os dois grupos de usuários das fontes (os especialistas e os não-especialistas) conseguem distinguir fontes de texto, e se atribuem conceitos subjetivos à elas. Posteriormente, buscaremos comparar os resultados dos dois grupos de usuários para entender as diferenças de percepção entre eles.

Os questionários, estruturados através do sistema online Qualtrics, são divididos em duas partes. A primeira é composta por perguntas relativas à comparação entre as fontes, e a segunda contempla questões relativas à associação de conceitos subjetivos aos tipos.

\section{As fontes escolhidas para a estruturação dos questionários}

Para a construção das perguntas que constituem o questionário foram selecionadas 12 fontes de texto presentes nos sistemas operacionais da Apple (OS X Mavericks) e da Microsoft (Windows 8), das quais metade possuem serifas e a outra metade não. As fontes escolhidas foram (Figura 01):

Figura 1: Fontes escolhidas para a formatação dos questionários (fonte: elaborada pelas autoras com base na pesquisa realizada).

FONTES SERIFADAS Baskerville, Bodoni, Garamond, Palatino, Rockwell e Times New Roman

FONTES NÃO-SERIFADAS Calibri, Futura Std, Gill Sans, Helvetica, Tahoma e Trebuchet MS

\section{Como as fontes foram estudadas}

Este estudo pretende explorar as possibilidades semânticas da tipografia no que diz respeito ao desenho dos caracteres, ou seja, apenas em seus aspectos intrínsecos. No entanto, esses 
desenhos podem ser analisados de diversas maneiras, de acordo com várias situações de uso específicas. Os questionários abordaram três situações de uso: a fonte na composição de uma mancha textual, a fonte na composição do alfabeto em suas versões maiúscula e minúscula, e por fim, alguns caracteres individuais das tipografias ("n", "o", "a" e "g").

Para a atribuição de conceitos subjetivos, utilizamos como suporte a proposta de análise de fontes de Falcão \& Aragão (2012), onde foram apresentados 8 grupos de conceitos (pessoalidade, elegância, peso, delicadeza, fluidez, tensão, época e excentricidade). Para este estudo, foram subtraídos os conceitos pessoalidade e tensão e revisitadas as expressões utilizadas para denominar os demais grupos. As perguntas relativas à atribuição de conceitos utilizam uma escala de 5 pontos entre os dois pólos extremos de características subjetivas (Figura 02).

Figura 2: Grupos de características subjetivas utilizados na pesquisa (fonte: elaborada pelas autoras com base na pesquisa realizada).

\begin{tabular}{|c|c|c|c|c|c|}
\hline \multirow{2}{*}{ Sofisticação } & Elegante & Pouco Elegante & Neutra & Pouco Informal & Informal \\
\hline & $\bigcirc$ & $\bigcirc$ & 0 & $\bigcirc$ & $\odot$ \\
\hline \multirow{2}{*}{ Peso } & Densa & Pouco Densa & Neutra & Pouco Leve & Leve \\
\hline & 0 & 0 & 0 & 0 & ○ \\
\hline \multirow{2}{*}{ Expressividade } & Delicada & Pouco Delicada & Neutra & Pouco Agressiva & Agressiva \\
\hline & $\bigcirc$ & ○ & 0 & 0 & 0 \\
\hline \multirow{2}{*}{ Movimento } & Estática & Pouco Estática & Neutra & Pouco Dinâmica & Dinâmica \\
\hline & 0 & 0 & 0 & 0 & 0 \\
\hline \multirow{2}{*}{ Época } & Tradicional & Pouco Tradicional & Neutra & Pouco Moderna & Moderna \\
\hline & 0 & 0 & 0 & 0 & 0 \\
\hline \multirow{2}{*}{ Espirito } & Excêntrica & Pouco Excêntrica & Neutra & Pouco Comum & Comum \\
\hline & 0 & 0 & 0 & 0 & 0 \\
\hline
\end{tabular}

A fim de evitar perguntas longas e cansativas para os participantes, e ainda assim contemplar todos os fatores previstos para a análise, foi definido que seriam aplicados quatro tipos de questionários (Figura 03), a serem divididos aos dois tipos de usuários. Desta maneira, cada tipo de questionário foi respondido por 20 participantes: 10 especialistas e 10 nãoespecialistas.

Figura 3: Tipos de questionários (fonte: elaborada pelas autoras com base na pesquisa realizada).

\begin{tabular}{|c|c|c|c|}
\hline Q1 & $\mathbf{Q 2}$ & $\mathbf{Q 3}$ & Q4 \\
\hline Apresentação & Apresentação & Apresentação & Apresentação \\
\hline Introdução & Introdução & Introdução & Introdução \\
\hline Comparação & Comparação & Comparação & Comparação \\
\hline $\begin{array}{c}\text { Aspecto 01 } \\
\text { Mancha tertual Serif } \\
\text { (6 imagens) }\end{array}$ & $\begin{array}{c}\text { Aspecto } 01 \\
\text { Mancha textual Serif } \\
\text { (6 imagens) }\end{array}$ & $\begin{array}{c}\text { Aspecto } 01 \\
\text { Mancha textual Serif } \\
\text { (4 imagens) }\end{array}$ & $\begin{array}{c}\text { Aspecto } 01 \\
\text { Mancha tertual Serif } \\
\text { (4 imagens) }\end{array}$ \\
\hline $\begin{array}{c}\text { Aspecto } 01 \\
\text { Mancha textual Não-Serif } \\
\text { (4 imagens) }\end{array}$ & $\begin{array}{c}\text { Aspecto } 01 \\
\text { Mancha textual Não-Serif } \\
\text { (4 imagens) }\end{array}$ & $\begin{array}{c}\text { Aspecto } 01 \\
\text { Mancha textual Não-Serif } \\
\text { (6 imagens) }\end{array}$ & $\begin{array}{c}\text { Aspecto } 01 \\
\text { Mancha textual Não-Serif } \\
\text { (6 imagens) }\end{array}$ \\
\hline $\begin{array}{c}\text { Aspecto } 02 \\
\text { Alfabeto Não-Serifadas } \\
\text { (6 imagens) }\end{array}$ & $\begin{array}{c}\text { Aspecto } 02 \\
\text { Alfabeto Não-Serifadas } \\
\text { (6 imagens) }\end{array}$ & $\begin{array}{c}\text { Aspecto } 02 \\
\text { Alfabeto Não-Serifadas } \\
\text { (4 imagens) }\end{array}$ & $\begin{array}{c}\text { Aspecto } 02 \\
\text { Alfabeto Não-Serifadas } \\
\text { (4 imagens) }\end{array}$ \\
\hline Aspecto 02 & Aspecto 02 & Aspecto 02 & Aspecto 02 \\
\hline $\begin{array}{l}\text { Alfabeto Serifadas } \\
\text { (4 imagens) }\end{array}$ & $\begin{array}{l}\text { Alfabeto Serifadas } \\
\text { (4 imagens) }\end{array}$ & $\begin{array}{l}\text { Alfabeto Serifadas } \\
\text { (6 imagens) }\end{array}$ & $\begin{array}{l}\text { Alfabeto Serifadas } \\
\text { (6 imagens) }\end{array}$ \\
\hline $\begin{array}{l}\text { Aspecto } 03 \\
\text { Letra n Serifadas } \\
\text { (4 imagens) }\end{array}$ & $\begin{array}{l}\text { Aspecto 03 } \\
\text { Letra o Serifadas } \\
\text { (4 imagens) }\end{array}$ & $\begin{array}{l}\text { Aspecto 03 } \\
\text { Letran Serifadas } \\
\text { (4 imagens) }\end{array}$ & $\begin{array}{l}\text { Aspecto 03 } \\
\text { Letra o Serifadas } \\
\text { (4 imagens) }\end{array}$ \\
\hline $\begin{array}{l}\text { Aspecto } 03 \\
\text { Letras a Serifadas } \\
\text { (6 imagens) }\end{array}$ & $\begin{array}{l}\text { Aspecto } 03 \\
\text { Letras } g \text { Serifadas } \\
\text { (6 imagens) }\end{array}$ & $\begin{array}{l}\text { Aspecto } 03 \\
\text { Letras a Serifadas } \\
\text { (6 imagens) }\end{array}$ & $\begin{array}{l}\text { Aspecto } 03 \\
\text { Letras } g \text { Serifadas } \\
\text { (6 imagens) }\end{array}$ \\
\hline Semântica & Semântica & Semântica & Semântica \\
\hline $\begin{array}{l}\text { Times New Roman } \\
\text { Mancha textual }\end{array}$ & $\begin{array}{c}\text { Baskerville } \\
\text { Mancha textual }\end{array}$ & $\begin{array}{c}\text { Tahoma } \\
\text { Mancha textual }\end{array}$ & $\begin{array}{c}\text { Futura } \\
\text { Mancha textual }\end{array}$ \\
\hline $\begin{array}{c}\text { Helvetica } \\
\text { Mancha tertual }\end{array}$ & $\begin{array}{c}\text { Calibri } \\
\text { Mancha textual }\end{array}$ & $\begin{array}{c}\text { Gill Sans } \\
\text { Mancha textual }\end{array}$ & $\begin{array}{c}\text { Trebuchet } \\
\text { Mancha textual }\end{array}$ \\
\hline $\begin{array}{c}\text { Times New Roman } \\
\text { Letras }\end{array}$ & $\begin{array}{c}\text { Baskerville } \\
\text { Letras }\end{array}$ & $\begin{array}{c}\text { Tahoma } \\
\text { Letras }\end{array}$ & $\begin{array}{l}\text { Futura } \\
\text { Letras }\end{array}$ \\
\hline $\begin{array}{c}\text { Rockwell } \\
\text { Mancha textual }\end{array}$ & $\begin{array}{c}\text { Palatino } \\
\text { Mancha textual }\end{array}$ & $\begin{array}{c}\text { Bodoni } \\
\text { Mancha textual }\end{array}$ & $\begin{array}{l}\text { Garamond } \\
\text { Mancha textual }\end{array}$ \\
\hline
\end{tabular}




\section{Estruturação dos questionários}

\section{Telas iniciais}

As telas iniciais estão presentes em todos os tipos de questionários. Elas apresentam o intuito e o universo da pesquisa e requerem alguns dados de identificação (Figura 04).

Figura 04: Telas iniciais dos questionários (fonte: elaborada pelas autoras com base na pesquisa realizada).
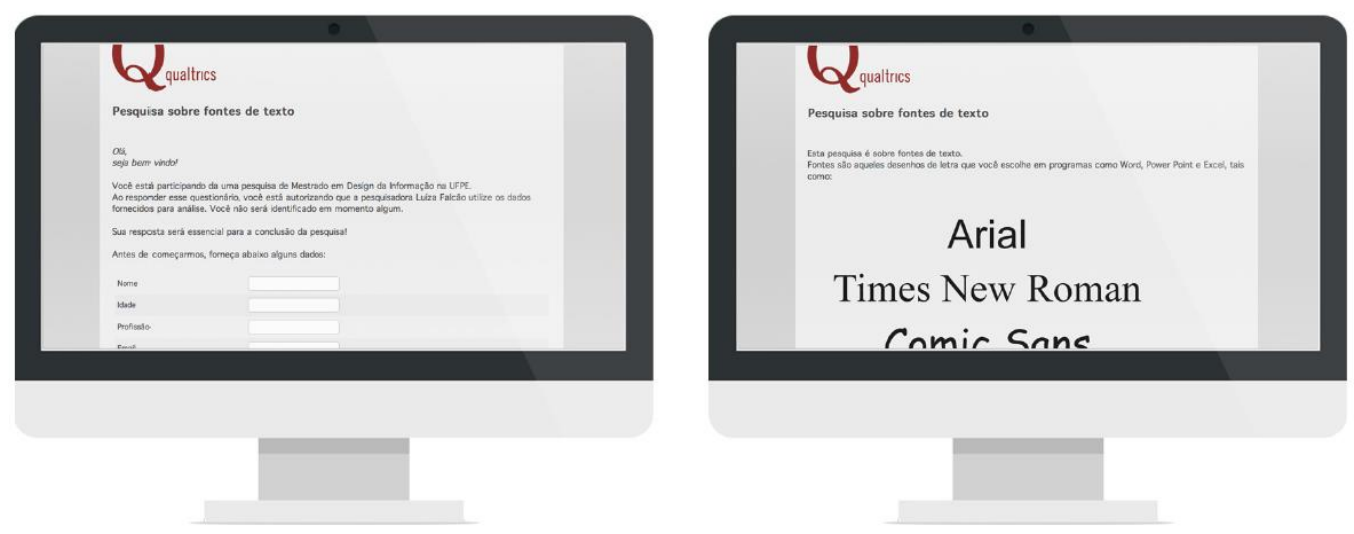

Telas da mancha textual

É a primeira fase de comparação entre as tipografias da pesquisa, onde cada fonte é utilizada numa mancha textual (Figura 05). Essa fase é composta por duas perguntas, e cada uma delas aparece em uma tela distinta. Uma das perguntas apresenta 4 imagens, cada uma delas expondo um texto composto com uma fonte diferente. A outra pergunta apresenta 6 imagens, e cada uma delas também expõe um texto composto com uma fonte diferente.

Figura 05: Telas de comparação entre manchas textuais (fonte: elaborada pelas autoras com base na pesquisa realizada).
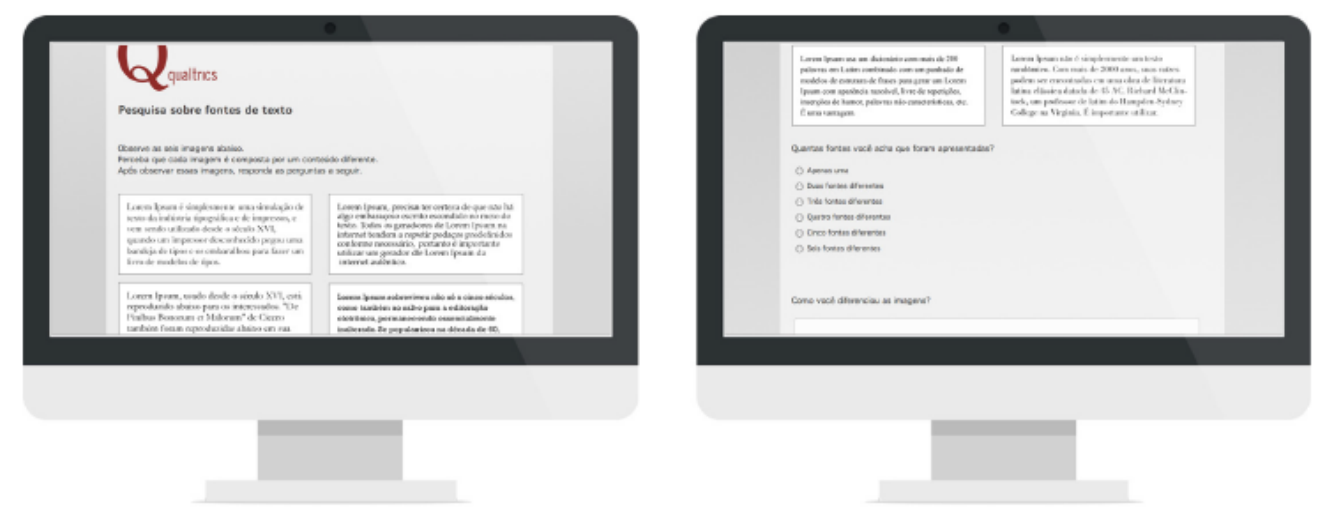

Alguns grupos de participantes foram apresentados a 4 imagens de fontes serifadas e 6 imagens de fontes não-serifadas, enquanto outros foram apresentados ao oposto. É importante destacar que as imagens não misturaram fontes serifadas com fontes não-serifadas, as comparações foram realizadas dentro de uma mesma categoria de tipos. Todas as imagens apresentadas nessa questão utilizam fontes distintas.

A forma como as alternativas foram apresentadas aos participantes também variou entre as duas perguntas. Algumas apresentaram suas opções dispostas em múltipla escolha, enquanto outras as apresentaram dispostas em forma de matriz. O intuito dessas variações de quantidade e formato é evitar que o usuário responda as questões de maneira automática, caso desconfie que as imagens possam ser as mesmas da questão anterior.

Os conteúdos dos textos das manchas textuais variam, porém sempre são iniciados pela expressão Lorem Ipsum e com as demais palavras escritas na língua portuguesa. As manchas textuais são alinhadas pela esquerda e os corpos das fontes ajustados de acordo 
com suas alturas-x, para evitar grandes discrepâncias relacionadas ao tamanho do texto. Os corpos utilizados estão localizados entre 12 e 16 pontos. A entrelinha também varia, para que as linhas dos textos ocupem uma área similar dentro da área determinada como suporte para a composição textual.

O questionário requisita a observação das imagens, salientando que cada uma delas utiliza um conteúdo textual diferente. Posteriormente, na mesma tela, é perguntado ao usuário quantas fontes diferentes ele acha que haviam sido utilizadas. Após a primeira das perguntas dessa fase é apresentada uma pergunta aberta que questiona como o participante diferenciou as imagens.

\section{Telas dos alfabetos maiúsculos e minúsculos}

Essa é a segunda fase de comparação entre as tipografias da pesquisa, onde cada fonte é utilizada na composição do alfabeto em caixa alta e caixa baixa (Figura 06). Sua estruturação e recursos de tamanho e alinhamento das fontes são idênticos à da situação de uso exposta anteriormente.

Figura 06: Telas de comparação entre alfabetos (fonte: elaborada pelas autoras com base na pesquisa realizada).
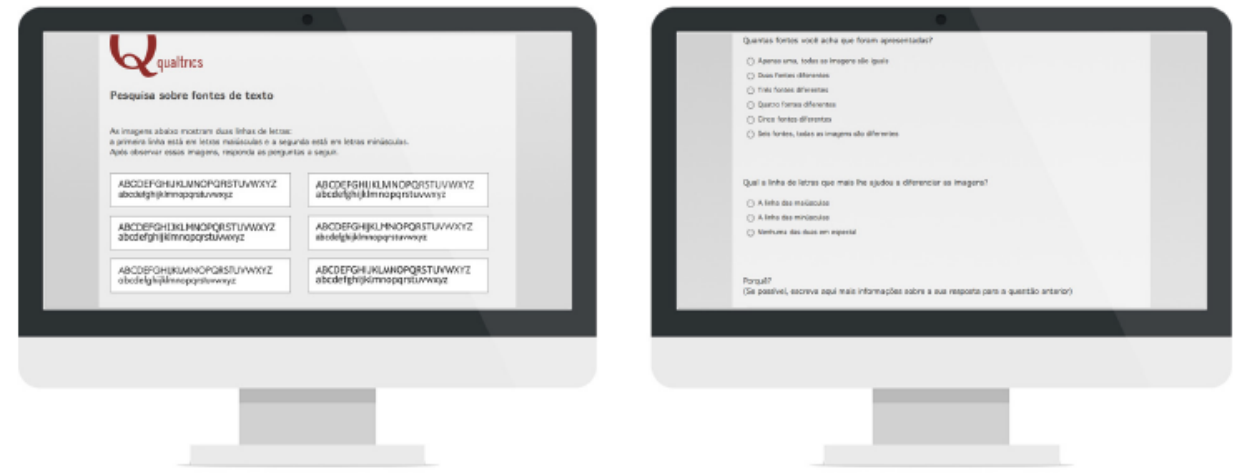

O questionário requisita a observação das imagens, salientando que cada uma delas está composta por duas linhas de letras: a primeira apresenta apenas letras maiúsculas e a segunda apresenta apenas letras minúsculas. Posteriormente, na mesma tela, é perguntado ao usuário quantas fontes diferentes ele acha que haviam sido apresentadas. Após a primeira das perguntas dessa fase é apresentada uma pergunta aberta que questiona qual a linha de letras que mais o ajudou a diferenciar as imagens, e o porquê.

\section{Telas das letras individuais (caracteres " $a$ " "g" " $n$ " $e$ "o")}

A terceira fase de comparação dos questionários é composta por letras individuais (Figura 07). Seu intuito é avaliar se os usuários conseguem perceber diferenças entre caracteres dispostos lado a lado em fontes diferentes, e quais as partes dos caracteres que os auxiliam a fazer essa distinção.

Figura 07: Telas de comparação entre caracteres específicos (fonte: elaborada pelas autoras com base na pesquisa realizada).
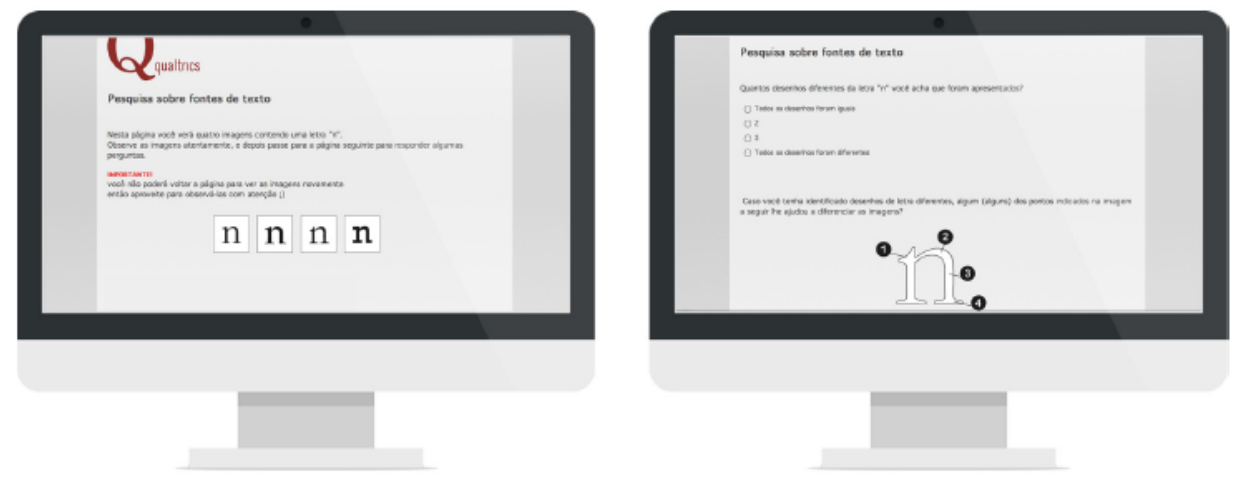
Primeiramente são apresentadas quatro imagens de uma mesma letra, utilizando fontes diferentes (caracteres "n" e "o"). As instruções do questionário sinalizam que o usuário dever observar cuidadosamente as imagens, e passar para a próxima página para responder algumas perguntas. Após a apresentação dos caracteres são apresentadas na tela seguinte as questões relativas às imagens das letras individuais. A primeira delas questiona quantos desenhos de letra diferentes o usuário havia identificado. Logo após, são mostrados diagramas para que o usuário responda se algumas das partes específicas das letras o ajudou a distinguir os desenhos.

A próxima pergunta dessa fase apresenta 6 imagens de uma mesma letra ("a" ou "g"), das quais uma se repetiu e as demais utilizam fontes distintas. $O$ intuito dessa repetição é incentivar o usuário a continuar atento às imagens mostradas. As instruções do questionário sinalizam que o usuário deve observar cuidadosamente as imagens, e passar para a próxima página para responder algumas perguntas. Após a observação dessas imagens, mais uma vez é questionado quantos desenhos de letra diferentes o usuário identificou e os diagramas dos respectivos caracteres. Os tamanhos dos caracteres estão localizados entre 62 e 73 pontos, aparecendo centralizados dentro de um quadrado de 65 pontos, um ao lado do outro.

\section{Telas das possibilidades semânticas das fontes (mancha textual)}

Aqui tem início a segunda fase dos questionários: os questionamentos acerca das possibilidades semânticas das fontes de texto. Cada uma dessas questões apresenta uma mancha textual (utilizando os mesmos textos das primeiras perguntas dos questionários) ou caracteres isolados ("a", " $g$ ", " $n$ " e "o") de uma fonte específica. Cada tipo de questionário possui 3 questões que apresentam manchas textuais, e 1 questão que apresenta caracteres isolados (Figura 08).

Figura 08: Telas de perguntas sobre a semântica das fontes de texto (fonte: elaborada pelas autoras com base na pesquisa realizada).
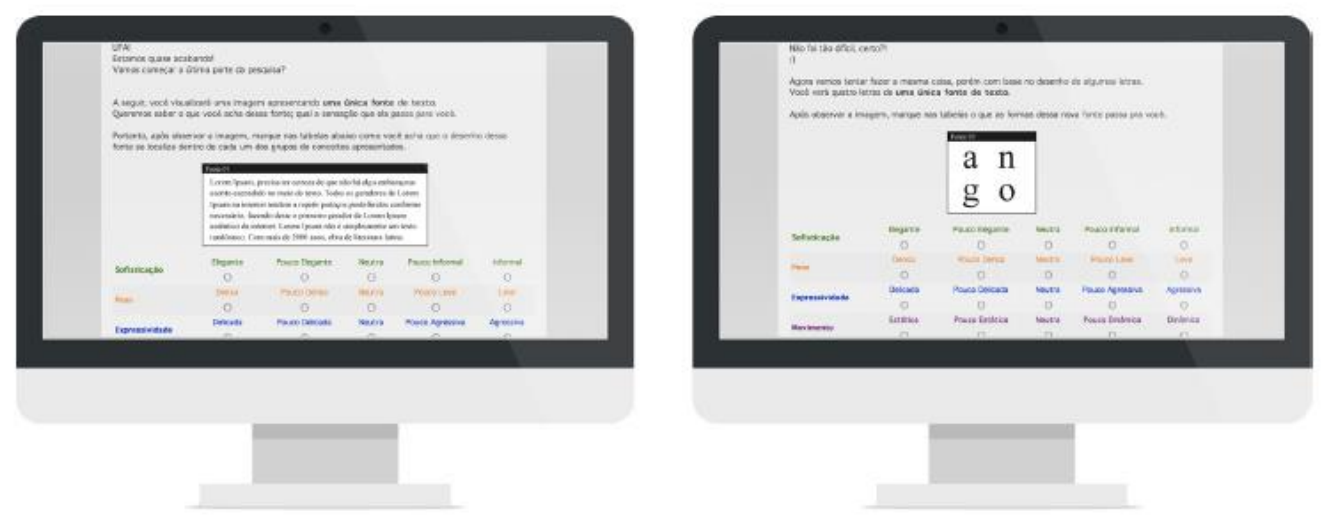

O intuito dessas questões foi avaliar se os dois grupos de usuários conseguem atribuir conceitos subjetivos às fontes de texto, e quais são as diferenças entre os conceitos atribuídos pelos dois tipos de participantes. Após as imagens, foram apresentados 6 grupos de conceitos (Sofisticação, Peso, Expressividade, Movimento, Época e Espírito) numa escala de 5 pontos entre seus extremos para marcação, onde o ponto central é considerado neutro.

As questões que apresentaram os caracteres isolados utilizam a mesma fonte utilizada na primeira questão sobre semântica (que mostrou uma mancha textual). A imagem é seguida pelos mesmos grupos de conceitos das questões anteriores. O intuito dessa questão é comparar o julgamento dos usuários entre a apresentação de uma mancha textual e de caracteres isolados. As fontes contempladas pela apresentação de caracteres isolados foram a Times New Roman, Baskerville, Tahoma e Futura, cada uma delas em um dos tipos do questionário. 


\section{Os resultados}

\section{Sobre a comparação entre fontes de texto}

A fase de comparação entre manchas textuais indicou que os usuários especialistas conseguem distinguir as fontes utilizadas na composição de textos com mais facilidade do que os usuários não-especialistas. De acordo com as informações coletadas, também é possível inferir que os usuários especialistas possuem mais facilidade para comparar manchas textuais compostas por fontes sem serifa (Figura 09).

Figura 09: Resultados das questões relativas às manchas textuais (fonte: elaborada pelas autoras com base na pesquisa realizada).

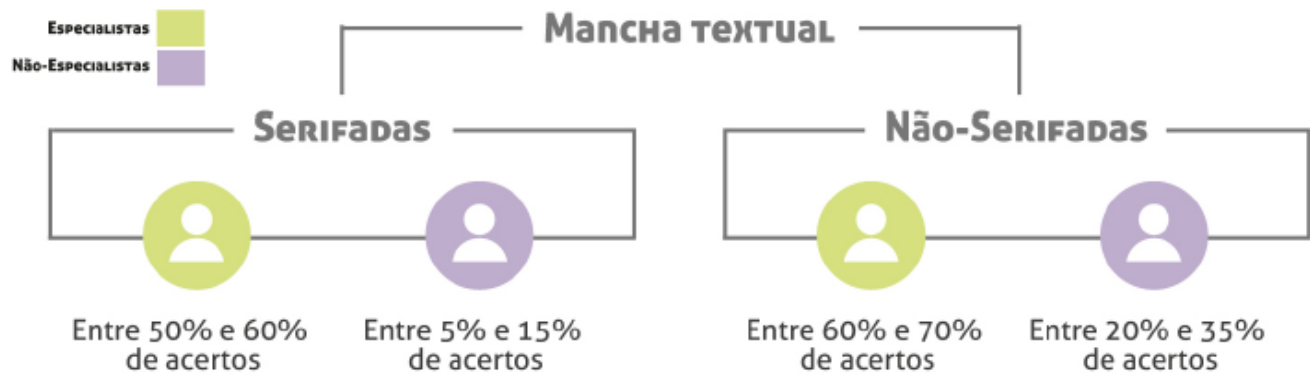

Os participantes não-especialistas obtiveram um número de acertos baixo nessas questões. Na questão de comparação entre 6 manchas textuais serifadas, apenas $5 \%$ dos usuários desse grupo conseguiram perceber que as fontes apresentadas eram diferentes. Nos comentários escritos sobre essas questões, menções à comparação entre caracteres específicos foram recorrentes nos dois grupos de usuários. E possível inferir que em muitas situações, os participantes utilizaram como critério final para a diferenciação das manchas textuais a comparação de letras específicas.

Nas questões relativas à comparação entre alfabetos (Figura 10), as respostas coletadas indicam que, assim como nas questões de comparação entre manchas textuais, os usuários especialistas conseguem distinguir com mais facilidade do que os usuários nãoespecialistas as fontes utilizadas. Pelo menos $80 \%$ dos especialistas conseguiram distinguir que os tipos utilizados nos alfabetos eram todos diferentes, chegando a atingir o número de acertos de $95 \%$ em uma das questões. Podemos afirmar que os dois grupos de participantes conseguiram comparar com mais facilidade os alfabetos do que as manchas textuais.

Figura 10: Resultados das questões relativas aos alfabetos (fonte: elaborada pelas autoras com base na pesquisa realizada).

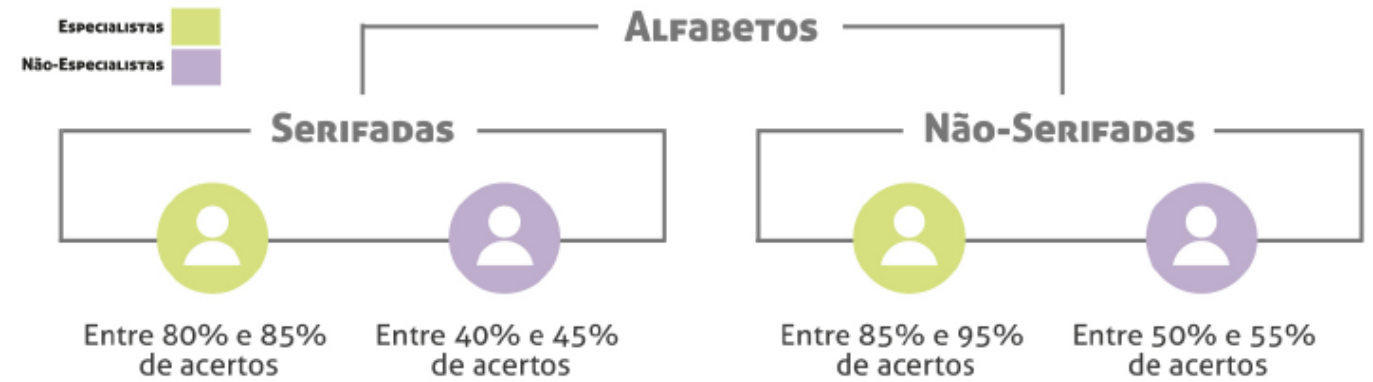

$\mathrm{Na}$ apresentação dos alfabetos, mais uma vez foi constatado que os dois grupos de usuários conseguiram perceber com mais êxito as diferenças entre as tipografias nãoserifadas. Nos comentários escritos, foi percebido que os usuários especialistas se utilizaram bastante da comparação entre os alfabetos em caixa baixa, tendência não observada na outra categoria de usuários. Menções à comparação entre os caracteres "G", "J", "Q", "a", "g", "j" e "y" foram recorrentes nos dois grupos de usuários. Entre essas letras, o "a", "g" e "Q" se destacaram por serem as mais citadas. 
Nas questões de comparação entre caracteres específicos, os caracteres "n" serifados revelaram-se como fáceis de serem diferenciados uns dos outros, especialmente pelos usuários especialistas. Todos os participantes dessa categoria que responderam essa questão conseguiram perceber que os caracteres pertenciam a fontes diferentes. No grupo dos usuários não-especialistas o índice de acerto foi de 70\% (Figura 11).

Figura 11: Resultados das questões relativas ao caractere " $n$ " (fonte: elaborada pelas autoras com base na pesquisa realizada).
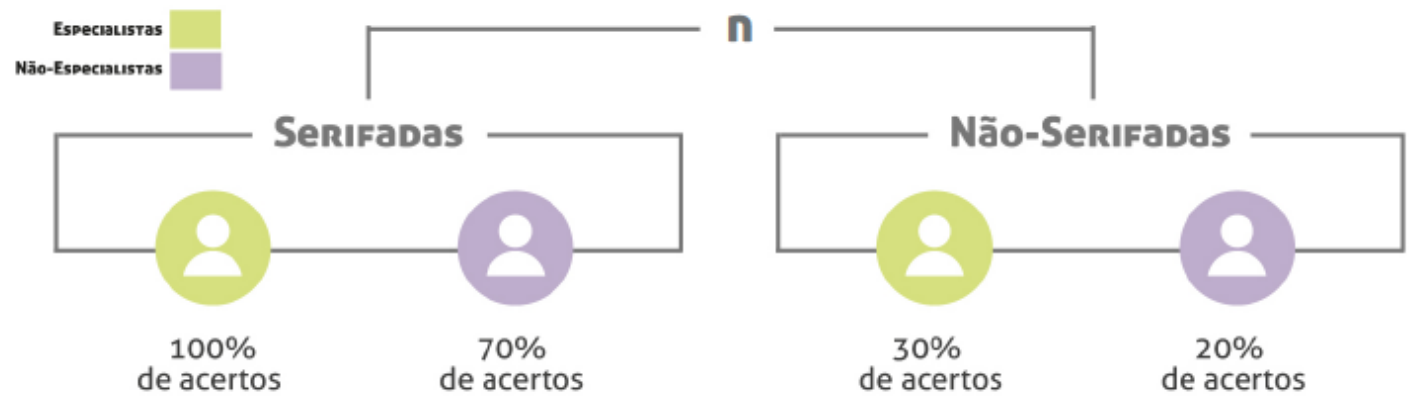

Na questão que utilizou caracteres "n" não-serifados, o número de acertos foi consideravelmente menor, nos dois grupos de usuários, não ultrapassando os $30 \%$. O fato sinaliza que acentuar as diferenças formais no desenho do caracteres "n" não-serifados, pode ser proveitoso para que a fonte adquira mais personalidade. Sobre quais os pontos da letra que mais ajudaram os usuários a distinguirem as tipografias, foi recorrente à menção à espora, nos caracteres serifados e não-serifados. Dessa maneira, é possível inferir que essa parte do desenho do caractere se revela como um local interessante para explorações formais.

Nas questões de comparação entre as letras "a" (Figura 12), o número de acertos dos usuários especialistas foi alto, tanto nas questões com letras serifadas quanto nas questões com letras não-serifadas. $\mathrm{O}$ grupo dos não-especialistas obteve uma margem de acertos satisfatória, nas duas questões, $40 \%$ nos caracteres serifados e $60 \%$ nos caracteres nãoserifados. As partes das letras mais observadas pelos dois grupos de participantes (o terminal e o remate) foram as mesmas nas letras com e sem serifa.

Figura 12: Resultados das questões relativas ao caractere "a" (fonte: elaborada pelas autoras com base na pesquisa realizada).
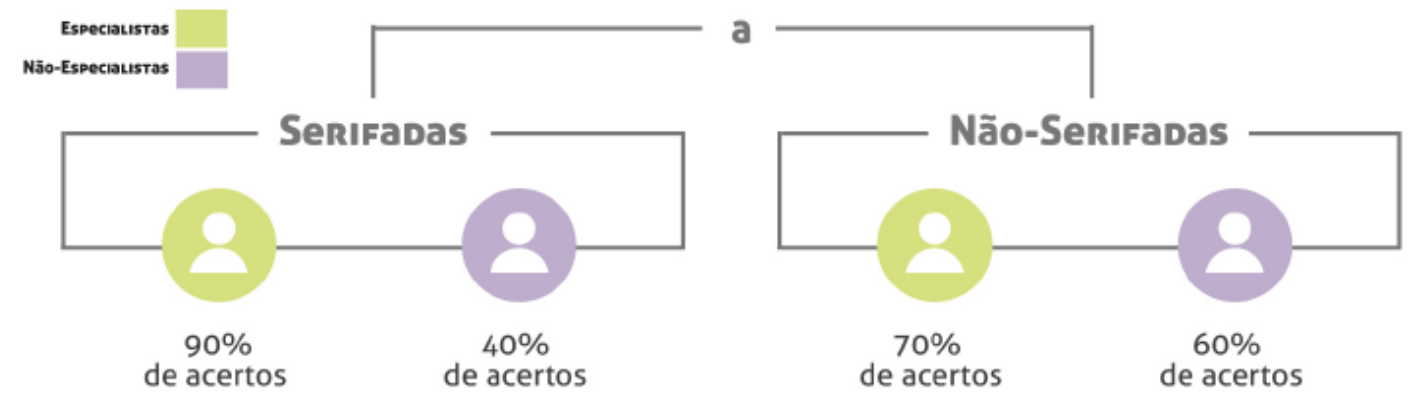

As questões de comparação entre os caracteres "o" foram, de uma maneira geral, as que obtiveram um maior número de acertos nos dois grupos de usuários (Figura 13). O fato levanta uma inquietação acerca do resultado dessa questão em especial: é difícil reconhecer até que ponto o tamanho utilizado para a apresentação dos caracteres nessas questões influenciou seus resultados, uma vez que o caractere "o" não foi citado pelos participantes nos comentários escritos das questões anteriores como um fator de diferenciação relevante. 
Figura 13: Resultados das questões relativas ao caractere "o" (fonte: elaborada pelas autoras com base na pesquisa realizada).
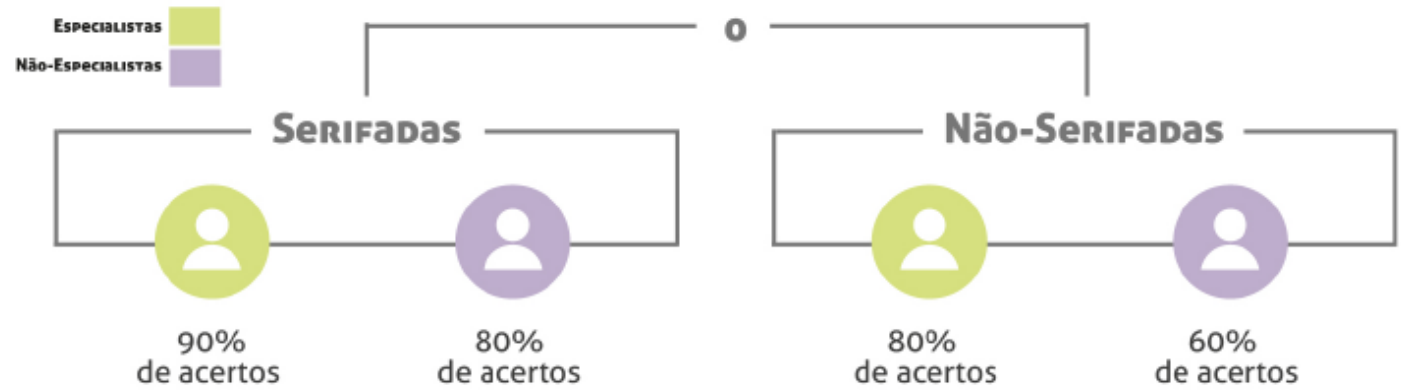

Nas questões de comparação entre as letras "g", o número de acertos dos usuários na questão dos caracteres não-serifados foi maior do que o número de acertos da questão dos caracteres serifados, nos dois grupos de usuários (Figura 14). Ainda assim, a quantidade de acertos revela que não existiu mais facilidade de diferenciação devido aos dois tipos de configuração apresentados: o arquétipo formal da letra humanista e outro com uma configuração mais simples. As questões anteriores, que apresentaram caracteres com arquétipos formais semelhantes, obtiveram um maior número de acertos. A orelha e $o$ arco foram as duas partes dos caracteres mais citadas pelos dois grupos de participantes. Por fim, a comparação entre os "g" com serifa foi a única questão na qual o grupo dos não-especialistas acertou mais que o grupo dos especialistas.

Figura 14: Resultados das questões relativas ao caractere "g" (fonte: elaborada pelas autoras com base na pesquisa realizada).
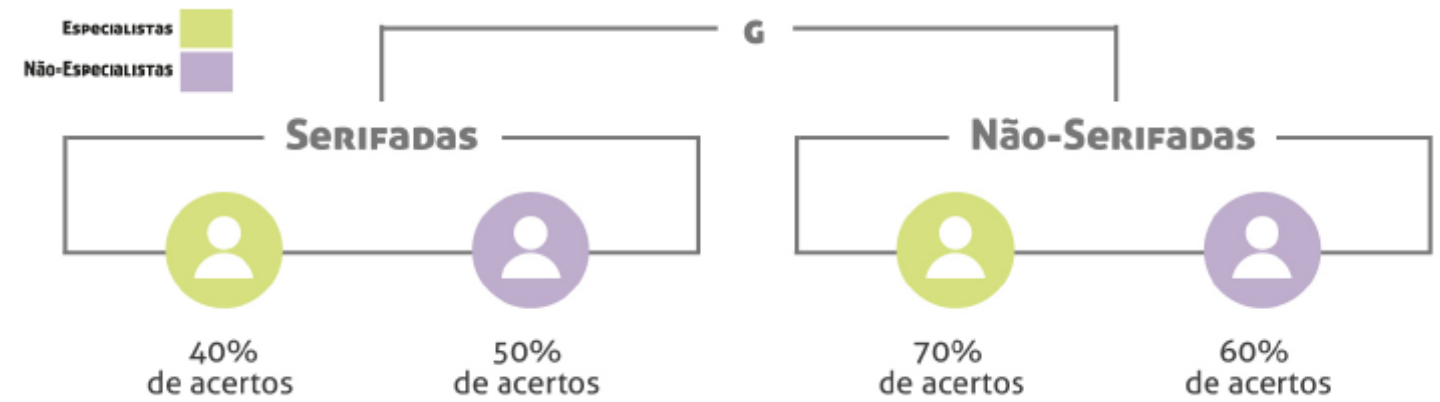

A apresentação do caractere "n" não-serifado se destaca entre todas as situações de uso. Foi a única situação onde os usuários possuíram mais dificuldade para distinguir as imagens apresentadas quando essas utilizavam fontes sem serifa.

As questões de comparação entre as fontes de texto indicam que os usuários especialistas conseguem diferenciar as tipografias com mais facilidade do que os usuários nãoespecialistas, nas três situações de uso apresentadas. No que diz respeito à percepção da mancha textual, ficou clara a dificuldade dos usuários não-especialistas em reconhecerem as diferenças entre as fontes apresentadas, devido ao baixo número de acertos do grupo nas questões dessa natureza.

\section{As possibilidades semânticas da tipografia do ponto de vista de seus usuários}

Nas questões relativas à atribuição de conceitos subjetivos às fontes, foi possível observar algumas tendências nas respostas dos dois grupos de usuários. É interessante destacar que de acordo com as informações recolhidas, os usuários pareceram atribuir mais facilmente conceitos subjetivos às fontes serifadas. Desta maneira, constatamos que apesar de distinguirem mais facilmente as tipografias não-serifadas, os usuários possuem mais dificuldade para julgar seus atributos de personalidade.

Nas análise das fontes serifadas foi observado que não houve divergência de opiniões entre os dois grupos de participantes no que diz respeito às atribuições de conceitos subjetivos às tipografias. Em alguns casos pontuais, apenas um dos grupos atribuiu um determinado 
conceito a uma determinada fonte. No entanto, nessas ocasiões, o outro grupo se distribuiu entre as opções apresentadas ou avaliou a fonte como neutra, fato que não caracteriza uma contradição.

Dentre as fontes serifadas analisadas pelos usuários, a Garamond foi a que apresentou o menor número de conceitos atribuídos. Apenas 2 dos 6 grupos conceituais passíveis de análise revelaram um consenso entre os participantes, os grupos sofisticação e época. $\mathrm{Na}$ ocasião, tanto os usuários especialistas quantos os não-especialistas consideraram a fonte elegante e tradicional. A fonte serifada que apresentou o maior número de conceitos atribuídos e consenso entre os dois grupos de participantes foi a Baskerville. Os participantes a consideraram elegante, delicada, tradicional e neutra quanto ao seu peso. A fonte Bodoni também se destacou pela quantidade de conceitos atribuídos. No entanto, alguns desses conceitos foram atribuídos apenas por um dos grupos de usuários, a exemplo dos conceitos pouco delicada e pouco dinâmica atribuídos apenas pelos usuários especialistas. Os conceitos elegante, leve e tradicional foram atribuídos à essa fonte pelos dois grupos de usuários (Figura 15).

Figura 15: Resultados das questões relativas à atribuição de conceitos subjetivos às fontes serifadas (fonte: elaborada pelas autoras com base na pesquisa realizada).
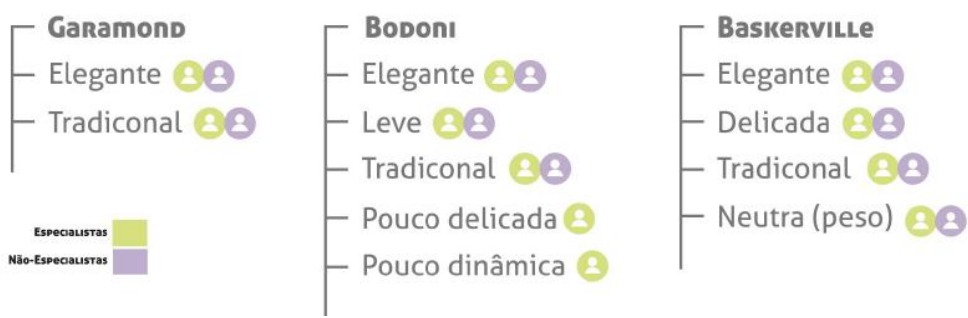

Nas fontes onde foram apresentadas duas situações de uso (mancha textual e caracteres isolados), foi observado que os conceitos atribuídos à mancha se mantiveram quando os usuários foram apresentados aos caracteres isolados. Muitas vezes, a gradação atribuída a uma das situações foi maior, a exemplo dos conceitos elegante/pouco elegante, atribuídos pelos dois grupos de usuários às manchas textuais da Times New Roman e da Baskerville. Ao serem apresentados aos caracteres isolados dessas fontes, observou-se uma maior concentração dos usuários nesses conceitos, o que sugere que os participantes consideram as letras isoladas mais elegantes do que a mancha textual. O fato levanta um questionamento acerca do motivo que acarretou a situação: se os usuários consideram, de fato, os caracteres mais elegantes, ou se acham mais fácil atribuir essa característica subjetiva a caracteres expostos isoladamente do que a uma mancha textual.

Dentre os 6 grupos conceituais apresentados (Sofisticação, Peso, Expressividade, Movimento, Época e Espírito), os grupos Sofisticação, Época e Expressividade foram os que possuíram maior consenso de escolha entre os participantes. Portanto podemos afirmar que, de acordo com as informações coletadas, os dois tipos de usuários são mais coesos ao atribuírem conceitos subjetivos referentes aos grupos sofisticação, época e expressividade, quando analisam uma fonte serifada. Sobre os conceitos específicos mais atribuídos a esse tipo de fontes, destacam-se as duplas elegante/pouco elegante e tradicional/pouco tradicional, atribuídas a 5 das 6 fontes apresentadas.

Nas análises das fontes não-serifadas foi observado que o grupo dos usuários especialistas foi mais coeso na atribuição dos conceitos subjetivos. Em algumas tipografias, tais como na análise da Gill Sans e da Futura, a concentração de usuários em conceitos específicos aconteceu apenas com os participantes desse grupo. Em nenhuma ocasião a opinião de um grupo foi contraditória a opinião do outro grupo de participantes; a situação mais recorrente foi a concentração de grande parte dos usuários de um grupo em um dos conceitos e a distribuição dos usuários do outro grupo ao longo das demais opções apresentadas.

As informações recolhidas ao longo da aplicação dos questionários indicam que o grupo dos usuários não-especialistas não foi coeso na atribuição de conceitos subjetivos às fontes não-serifadas. Ao longo da primeira fase dos questionários, foi detectado que este grupo possuiu dificuldade para distinguir as fontes quando utilizadas em manchas textuais. No entanto, apesar dessa dificuldade na fase de comparação, esse grupo de participantes atingiu 
altos níveis de concentração de usuários em um mesmo conceito, na observação das fontes serifadas.

O fato indica que tal grupo de usuários possui opinião divergente no tocante à atribuição de conceitos subjetivos às fontes não-serifadas, porém conseguem ser mais coesos nesse aspecto quando são apresentados à fontes serifadas.

Nas fontes que foram apresentadas em manchas textuais e em caracteres isolados, foi observado que os conceitos atribuídos à mancha textual se mantiveram ou apenas se deslocaram para a opção neutra quando os usuários foram apresentados aos caracteres específicos. Portanto, não foi possível detectar se a alternância da observação entre uma macha textual e alguns caracteres específicos acarreta diferenças explícitas na percepção dos grupos de usuários de uma determinada fonte.

\section{Considerações Finais}

A proposta básica desse estudo é entender se os dois tipos de usuários das fontes de texto, os especialistas e os não-especialistas, conseguem identificar diferenças entre tipografias dessa natureza, e se conseguem atribuir conceitos subjetivos às mesmas.

De acordo com as respostas recolhidas ao longo da aplicação dos questionários, foi constatado que os usuários não-especialistas não conseguiram distinguir que as manchas textuais apresentadas utilizavam fontes diferentes umas das outras. Desta maneira, antes de entrarmos na esfera da interpretação semântica dos tipos de texto, podemos constatar que ao contrário dos usuários especialistas, tais usuários não conseguem diferenciar fontes de texto apresentadas em manchas textuais (principalmente nas que utilizam fontes serifadas). Nas outras situações de uso apresentadas (a fonte na composição do alfabeto em suas versões maiúsculas e minúsculas, ou apresentada em alguns caracteres específicos), foi observado que esses usuários conseguiram distinguir as fontes mais facilmente.

Portanto, surge aqui um fato interessante a ser investigado em futuras pesquisas - os usuários não-especialistas não conseguem distinguir manchas textuais compostas com fontes diferentes quando apresentadas uma ao lado da outra, porém conseguem atribuir conceitos subjetivos ao serem apresentados às manchas individualmente, conforme foi constatado na última fase dos questionários. A partir dessa informação, é possível inferir que apesar de não perceberem que determinadas fontes são diferentes umas das outras, os usuários nãoespecialistas são capazes de perceber alguns conceitos subjetivos a partir delas.

No que diz respeito às diferenças de interpretação dos dois grupos de usuários frente às fontes apresentadas, foi observado que não houve divergência de opiniões entre os participantes. $\mathrm{Na}$ análise das tipografias serifadas, os dois grupos de usuários atribuíram os mesmos conceitos (ou conceitos afins) às fontes analisadas. Na análise das fontes nãoserifadas, foi observado que o grupo dos especialistas teve mais facilidade em elencar os conceitos subjetivos capazes de descrever as tipografias.

$\mathrm{Na}$ fase de atribuição de conceitos subjetivos às fontes utilizadas, é possível perceber que as fontes serifadas foram classificadas em diversas ocasiões como elegantes - apenas uma delas, a Rockwell, foi classificada como informal. A fonte se destaca dentre as demais tipografias do conjunto pois é a única do grupo que possui serifas egípcias, também sendo classificada pelos usuários especialistas e não-especialistas como densa e pouco agressiva. Esses conceitos não foram atribuídos a nenhuma outra fonte analisada. A marcação da opção neutra foi recorrente na análise das fontes não-serifadas, em todos grupos conceituais, com exceção do grupo época.

É importante destacar mais uma vez que este estudo lidou apenas com a microtipografia (Stolckl, 2005), excluindo portanto a possível influência dos demais elementos que acompanham uma mensagem textual, até mesmo o conteúdo do texto.

Assim, percebe-se que foi possível alcançar os objetivos propostos pelo presente estudo através dos métodos empregados, ainda que não tenha sido possível esgotar a discussão sobre as possibilidades semânticas das fontes de texto. Um estudo mais aprofundado sobre a temática da presente pesquisa poderá contribuir para um melhor entendimento das potencialidades significativas das formas tipográficas, e colaborar com 
informações relevantes tanto ao processo projetual de fontes de texto quanto à etapa de seleção de fontes no projeto de um artefato gráfico.

\section{Agradecimento}

Gostaríamos de agradecer aos designers Crystian Cruz, Deiverson Ribeiro, Eduilson Coan, Fabio Haag e Ricardo Esteves, por concederem seu tempo para a realização das entrevistas que embasaram a elaboração dos questionários. Agradecemos também a todos que responderam à pesquisa.

\section{Referências}

BRUMBERGER, E. 2003. The Rhetoric of Typography - The awareness and Impact of Typeface Appropriatness. Technical Communication; May 2003; 50, 2; Humanities Module.

DYSON, M. \& STOTT, C. 2012. Characterizing typographic expertise: Do we process typefaces Like Faces? Visual Cognition Volume 20, Issue 9, 2012.

FALCÃO, L. \& ARAGÃO, I. 2012. Um estudo entre forma e conteúdo em livros de literatura: uma proposta de análise. Anais do 10ํㅡㄹ Congresso Brasileiro de Pesquisa e Desenvolvimento em Design, São Luís (MA)

FALCÃO, L. \& ARAGÃO, I. 2013. Um estudo entre forma e conteúdo em livros de literatura da Cosac Naify. In: Anais do 6ํㅡㄹ Congresso Nacional de Iniciação Científica em Design da Informação (CONGIC), Recife (PE)

Li, Y \& SUEN, C. 2010. Typeface Personality Traits and Their Design Characteristics. DAS '10 Proceedings of the 9th IAPR International Workshop on Document Analysis Systems.

MACKIEWICZ, J \& MOELLER, R. 2004. Why people consider typefaces to have different personalities. Professional Communication Conference, 2004. IPCC 2004. Proceedings. International

STOCKL, H. 2005. Typography: body and dress of a text - a signing mode between language and image. Visual Communication, v. 4, n.2.

VAN LEEUWEN, T. 2006. Towards a semiotics of typography. Information Design Journal \& Document Design, 14(2), 139-155.

VAN LEEUWEN, T. 2005. Typographic meaning. Visual Communication, 4(2), 137-143.

\section{Sobre o(a/s) autor(a/es)}

Luiza Falcão, Mestre, UFPE, Brasil <luizafsc@gmail.com>

Solange Coutinho, PhD, UFPE, Brasil <solangecoutinho@globo.com> 